\title{
Opportunities for Improved Serodiagnosis of Human Tuberculosis, Bovine Tuberculosis, and Paratuberculosis
}

\author{
Ashutosh Wadhwa, Graham J. Hickling, and Shigetoshi Eda \\ Department of Forestry, Center for Wildlife Health, Wildlife and Fisheries, University of Tennessee Institute of Agriculture, \\ Knoxville, TN 37996, USA \\ Correspondence should be addressed to Shigetoshi Eda, seda@utk.edu
}

Received 29 January 2012; Accepted 2 April 2012

Academic Editor: Mitchell Palmer

Copyright ( $\odot 2012$ Ashutosh Wadhwa et al. This is an open access article distributed under the Creative Commons Attribution License, which permits unrestricted use, distribution, and reproduction in any medium, provided the original work is properly cited.

\begin{abstract}
Mycobacterial infections - tuberculosis (TB), bovine tuberculosis (bTB), and Johne's disease (JD)—are major infectious diseases of both human and animals. Methods presently in use for diagnosis of mycobacterial infections include bacterial culture, nucleic acid amplification, tuberculin skin test, interferon- $\gamma$ assay, and serology. Serological tests have several advantages over other methods, including short turn-around time, relatively simple procedures, and low cost. However, current serodiagnostic methods for TB, bTB and JD exhibit low sensitivity and/or specificity. Recent studies that have aimed to develop improved serodiagnostic tests have mostly focused on identifying useful species-specific protein antigens. A review of recent attempts to improve diagnostic test performance indicates that the use of multiple antigens can improve the accuracy of serodiagnosis of these mycobacterial diseases. Mycobacteria also produce a variety of species-specific nonprotein molecules; however, only a few such molecules (e.g., cord factor and lipoarabinomannan) have so far been evaluated for their effectiveness as diagnostic antigens. For TB and bTB, there has been recent progress in developing laboratory-free diagnostic methods. New technologies such as microfluidics and "Lab-onChip" are examples of promising new technologies that can underpin development of laboratory-free diagnostic devices for these mycobacterial infections.
\end{abstract}

\section{Introduction}

Mycobacterial infections are a leading cause of health concerns in humans and animals worldwide. Mycobacterium tuberculosis (MTB), Mycobacterium bovis (MB), and Mycobacterium avium subspecies paratuberculosis (MAP) are the causative agents of human tuberculosis (TB), bovine tuberculosis (bTB), and Johne's disease (JD), respectively. In 2009, more than 9 million cases of TB were reported, causing 1.8 million deaths [1]. Multidrug-resistant TB strains and coinfections of TB and HIV are emerging problems globally [2-4]. Despite much progress in eradicating bTB in developed countries, this disease is responsible for US\$ 3 billion economic losses globally [5] and remains prevalent in some wild species [6, 7]. MAP is present in $68 \%$ of US dairy herds [8], with JD responsible for an annual \$220 million economic loss to the US dairy industry [9].
Control measures for these mycobacterial diseases revolve around understanding their epidemiology and improving treatment/vaccination protocols; however, a major bottleneck has been the lack of efficient diagnostic methods [2, 10-12]. Consequently, there would be much benefit to the development of rapid and accurate diagnosis of TB at point-of-care [3] (In this paper, point-of-care diagnosis is defined as diagnostic methods that can be conducted on-site (e.g. field, bed-side), with or without a requirement for laboratory facilities. Laboratory-free (lab-free) diagnosis is defined as point-of-care diagnostic methods that does not require any laboratory facility). Similarly, the most common current diagnostic test for bTB, the tuberculin skin test (TST), is not practical for controlling bTB in wild animals, so a lab-free diagnostic device would also be helpful in this context. Diagnosis of JD is currently conducted annually or biannually in diagnostic laboratories. If a lab-free diagnostic 
device became available, it would reduce the long time interval and cost of diagnosis. Thus, there would be a great value in lab-free diagnostic technologies for TB, bTB, and JD $[13,14]$.

Unfortunately, efficient lab-free diagnostic devices for these diseases are not yet available $[14,15]$. Here, therefore, we briefly review currently available and recently developed diagnostic methods for these three mycobacterial diseases and highlight the potential benefits of lab-free diagnosis. Since serodiagnosis has been the most favored format for development of lab-free diagnostic method, we focus in this paper on methods of serodiagnosis over other diagnostic methods such as bacterial culture and nucleic acid amplification that are necessarily laboratory based.

\section{Human Tuberculosis}

2.1. Background. Human tuberculosis (TB) is caused primarily by MTB and occasionally by $\mathrm{MB}$ and $M$. africanum (in this paper we focus on MTB). TB is a leading cause of human morbidity and mortality throughout the world [16]. One-third of the world's population is infected by MTB [1], although only $5-10 \%$ of infected individuals develop an active, life-threatening form of the disease. In 2009, 9.4 million cases of TB were reported with 1.8 million deaths worldwide $[1,2,17]$.

Depending on the pathogenesis, infectivity, immune response, and effectiveness of treatment, TB can be divided into 3 major forms. The first is the active form of TB (TBA), which results in a rapid development of clinical signs in patients following contact with MTB. TBA develops in only $5 \%$ of individuals infected with MTB; the remainder develops a strong acquired immune response showing no clinical signs, termed latent TB (TBL) [18]. The third form is multidrug-resistant TB (MDRTB), which constitutes approximately $5 \%$ of TBAs [19]. MDRTB is caused by organisms resistant to, at least, isoniazid and rifampin [20]. The overall prevalence of MDRTB in developed nations is much lower than that in developing nations, but can be high in immigrant populations and among prisoners and immunocompromised individuals $[21,22]$. During the past two decades, the emergence of HIV infection has led to the recognition that $\mathrm{TB} / \mathrm{HIV}$ coinfection promotes both the reactivation of TBA from TBL and also the rapid progression of primary TB following recent exposure to MTB [23].

Controlling TB depends on the following factors: case detection, treatment of individuals with TBA, improving anti-TB therapy to prevent resistance, identification of TBL, and better vaccination strategies for susceptible individuals [16]. All these factors would benefit from a better understanding of the epidemiology of the TB infection [21] and the development of more cost-effective, evidence-based approaches for its diagnosis [22]. Efficient diagnosis of TB is particularly important in third world nations that presently lack adequate diagnostic resources at primary health care centers. In these nations, TBL and MDRTB often remain undiagnosed, which facilitates further transmission.

Presently, there are a number of alternative diagnostic approaches towards diagnosis of $\mathrm{TB}$ and of $\mathrm{TB}$ coinfection with other emerging infectious diseases; these are reviewed briefly here.

2.2. Imaging and Microscopic Techniques. Radiographic imaging is still widely used to diagnose TB; however, there are no definitive diagnostic patterns, so that the method can be used only for screening of TB cases. Further bacteriological examinations are required for confirmation $[64,65]$. Smear microscopy of stained sputum or other clinical material is the most common test for TBA. This relatively inexpensive method can be carried out rapidly in low-resource settings; however, it lacks sensitivity and requires a large number of bacilli $(5,000-10,000$ organisms/sample) $[64,66]$ in the clinical specimen, which is often not the case in children, advanced-stage TBA patients, and individuals coinfected with HIV. Fluorescent microcopy is more sensitive, but its application is limited by high cost and by issues relating to the use of mercury vapor lamps in conventional fluorescent microscopes [67]. Nucleic acid amplification (NAA) assays have been found useful for diagnosis of TBA and MDRTB infections, as they have high specificity and sensitivity and can provide results within a few hours. Unfortunately, these assays are costly, require a laboratory with trained staff, and suffer from poor specificity under field conditions $[64,68,69]$.

2.3. Bacterial Culture and Cell-Mediated Immune-ResponseBased Testing. Bacterial culture is considered the gold standard for TBA diagnosis, having close to $98 \%$ specificity, and is also useful in diagnosis of MDRTB. However, the bacterial culture method suffers from low sensitivity (26$42 \%$ ), delayed results (6-8 weeks are required for culture growth), a need for trained personnel and culture facilities, and the high cost of the culture examination. The need for technical expertise can be particularly problematic in developing nations. Parsons et al. have recommended new technologies including urine antigen detection, assays based on volatile markers, bead-based, and flow-cytometric-based assays [3] — to help address these problems, but these assays await optimization and establishment of clinical utility.

The tuberculin skin test (TST) - based on detection of delayed-type hypersensitivity after an intradermal injection of purified protein derivative (PPD) extracted from heat killed MTB - has been in use for almost a century. The primary roles of TST are to identify TBL individuals and to monitor recent infection in high-risk groups. Some limitations of TST include a high frequency of false reactions, the need for a follow-up visit after 2-3 days of PPD inoculation, misleading results due to confounding factors (e.g., age, HIV infection, and infection with other mycobacterial species or cancer), and positive reactions in TBA patients $[64,67,70]$. Based on the identification of MTB-specific antigens using molecular techniques, detection of cell-mediated immune (CMI) response against MTB infection has improved the diagnosis of TB. These assays measure the production of cytokines (mainly interferon-gamma [IFN- $\gamma]$ ) produced by $\mathrm{T}$ cells of MTB-infected individuals. Initial IFN- $\gamma$ assays were based on PPD antigen, but later the antigen was replaced by MTB-specific antigens, such as early-secreted 
antigenic target (ESAT-6) and culture filtrate protein (CFP10) [71]. IFN- $\gamma$ assays do provide an improved diagnosis of TBL; however, since they detect the presence of the host's CMI response towards MTB antigens, fresh blood samples are required for the test. Inability to differentiate between TBA and TBL, poor reproducibility, and reduced efficacy in children are additional problems of the CMIbased diagnostic tests [72]. In developing countries, TST is still preferred over IFN- $\gamma$ assay due to its lower cost but suffers from low efficacy in children, poor reproducibility, and reduced diagnostic accuracy for TBL [72-74].

2.4. Humoral-Immune-Response-Based Testing. In circumstances where medical resources (facilities and health care providers) are limited, serodiagnostic methods for detection of anti-MTB antibodies have some advantages (i.e., simplicity, low cost, and requirement of minimum medical resources) over aforementioned diagnostic methods [75]. Several target molecules (antigens) have been used to detect the humoral responses (anti-MTB antibodies) in TB patients. Early assays used PPD or other crude extracts as antigens for capturing anti-MTB antibodies; however, these showed poor specificity as dominant antibody responses are against cross-reactive antigens (i.e., antigens commonly found in MTB and also in other mycobacteria) [24]. As molecular techniques have improved, many antigens have been evaluated in serological tests, especially in the format of the enzyme-linked immunosorbant assay (ELISA). Some major antigens used in such tests are discussed below.

Antigen 5, also known as $38 \mathrm{kDa}$ antigen, is the best studied and most available antigen for MTB diagnosis due to its expression in the E. coli system. Many attempts to develop an improved serological assay for TB have used this antigen [30, 76]. Early studies reported $89 \%$ sensitivity and $100 \%$ specificity in TBA patients [31]. Later studies showed even higher sensitivity and demonstrated a correlation between antibody level and bacterial load [7780]. As summarized in a review article [81], detection of antibodies against Antigen85 complex in ELISA formats achieves $50 \%$ sensitivity; however, this complex is highly cross-reactive and often generates false-positive results in individuals infected with atypical mycobacteria. A cell wall component, called a cord factor (trehalose-6,6'-dimycolate), used as antigen in ELISA format achieved $84 \%$ sensitivity with $100 \%$ specificity [32]. However, in a subsequent study, it was shown that anticord factor antibodies decline after antituberculous chemotherapy, which makes it difficult to determine the status of the infection in such patients [33]. Studies of the serodiagnostic potential of ESAT-6 $[34,35]$ and CFP-10 [34, 35, 39, 40] have also been conducted. One showed low sensitivity (67\%) and specificity (51\%) for ESAT-6 [34]. Low sensitivity (48-63\%) also has been reported for CFP-10 [34, 82]. In high incidence areas, neither ESAT-6 nor CFP-10 antigens are useful in differentiating between TBA and TBL [34]. Another antigen, Kp 90, has been used in ELISA format to detect IgA antibodies against the protein; the results, when compared with NAA and other serological assays, indicated that anti-Kp 90 antibodies were detected in $78 \%$ of serum samples and $69 \%$ of samples from synovial, cerebrospinal, and abscess body fluids [41].

Antigen 60 (A60) is the main thermostable component of PPD $[83,84]$. Many studies have used this antigen and found almost $100 \%$ specificity [42], with sensitivity ranging from 68 to $91 \%[43,85]$. Unfortunately, this molecule has also been found in nonpathogenic Nocardia and Corynebacterium species [83]. A $30 \mathrm{kDa}$ antigen (isolated from a culture filtrate of MTB, Antigen 85B) was used in dot immunoassay, and the result was compared with that of standard plate ELISA. The specificities of the dot immunoassay and ELISA were $92 \%$ and $97 \%$, respectively, and the sensitivities in the assays were $69 \%$ and $78 \%$, respectively [44]. Further studies showed that this antigen not only diagnosed TBA but also detected the nonprotective immune response of a healthy household contact group [86].

Malate synthase (MS), a $81 \mathrm{kDa}$ protein (present in MTB culture filtrates, cell wall, and cytoplasmic subcellular fractions) is an enzyme of the glyoxylate pathway used by MTB during intracellular replication in macrophages [50]. Studies with an MS-based assay have shown a sensitivity of $73 \%$ and specificity of $98 \%$ in smear positive patients, suggesting that MS is a potential candidate for TB diagnosis $[82,87]$. The cell wall of MTB also contains lipoarabinomannan (LAM); however, its use as antigen in diagnostic tests is limited due to immune complex formation [3]. LAM antigen is found in urine of TBA patients, and tests based on detecting the LAM in urine samples have been developed $[46,88,89]$.

Steingart et al. conducted an intensive meta-analysis of 67 studies published in 1990-2006 on commercial serological tests for TBA (e.g., Detect-TB, and a-TB ELISA, ICT TB test) [75]. Antigens used in the commercial tests include Antigen 60, 38-Kda protein, LAM, and Kp-90. The meta-analysis revealed that estimated diagnostic sensitivities $(0-100 \%)$ and specificities (31-100\%) in the studies were inconsistent and imprecise, which is consistent with a WHO report in 2008 [90].

In patients coinfected with HIV and MTB, the level of antibody production to TB antigens differs from that of HIV-negative TB patients. For example, an ELISA based on MS/MPT51 antigens showed positive reactions in approximately $80 \%$ of HIV-positive, TB-positive patients and in $42 \%$ of HIV-negative, TB-positive patients [51]. Wanchu suggested that better diagnosis of TB will require a focus on development of multi-antigen-based tests and identification of novel MTB proteins that increase in HIV patients [91].

2.5. Point-of-Care Diagnosis and Future Directions. The studies described above indicate the need for an improved diagnostic test that is better able to differentiate the three forms of TB infection and to diagnose TB in the presence of HIV infection. Furthermore, since most deaths due to TB occur in developing countries that lack proper laboratory facilities and specialist training, it is important to develop a simple, rapid, and cost-effective test. The Xpert MTB/RIF assay has been recently used as point-of-care diagnosis for MDRTB and drug-sensitive TB $[92,93]$. Although simple to perform and highly sensitive, this assay is costly [94]. McNerney and Daley have summarized the importance of 
point-of-care diagnosis [95] and suggest three important areas in which progress should be made to achieve better point-of-care for TB. The first is through identification of biological, metabolic, and pathogen-derived markers that will assist in understanding the disease. The second is the development of effective technologies like immunochromatography and nanotechnology. The third is to better understand the economical and logistic constraints on the implementation of new tests [95]. In summary, there is an urgent need to develop a lab-free diagnostic device for TB that will decrease disease transmission rate, reduce death rates, and permit faster initiation of treatment.

\section{Bovine Tuberculosis}

3.1. Background. Bovine tuberculosis (bTB), caused by Mycobacterium bovis (MB), is an infectious, chronic but progressive disease characterized by the formation of granulomatous lesions with varying degrees of necrosis, calcification, and encapsulation [11]. MB is known to infect and cause tuberculosis in a wide range of wild animals, livestock animals, and humans. Although bTB has been mostly eradicated in the livestock industry of developed countries, the disease in wildlife still poses a risk to livestock, tourism economy, and wildlife conservation [11]. Infected wildlife species include white-tailed deer (Odocoileus virginianus) in several states of the USA, Eurasian badgers (Meles meles) in Great Britain and the Republic of Ireland, and brushtail possums (Trichosurus vulpecula) in New Zealand [6]. Global economic losses from bTB total US\$ 3 billion annually [5]. In the USA, US\$ 40 million and in Great Britain $\mathfrak{£} 100$ million were spent on bTB management in the year 2008-2009 alone [5]. In developing countries, bTB still causes serious concerns not only for wildlife, but also for public health, food safety, and the economy of livestock industries. More accurate diagnosis of bTB would reduce the unnecessary sacrifice of healthy animals and would also help to more effectively control bTB. At present, postmortem diagnosis based on examination of gross lesions, followed by histopathology and culture, is widely used for surveillance of bTB in wild animals, but this method is time-consuming and cannot diagnose an early infection [96].

3.2. Cell-Mediated Immune-Response-Based-Testing. The ante mortem diagnostic method currently prescribed by OIE is the intradermal tuberculin skin test (TST) [97]. The TST is by far the most effective test used in the eradication of bTB in the developing countries. The test is performed by injecting a small volume of bovine tuberculin in the skin of the animal and palpating a change in the thickness of the skin at the site of injection after $48-72$ hours. The tuberculin used in most of the countries is derived from cultures of MB AN5, a field strain isolated in England circa $1948[5,26,96]$. The TST is, however, susceptible to causing false-positive reactions due to exposure of some animals to environmental mycobacteria such as $M$. avium and MAP $[96,98-100]$. TST can also cause false-negative reactions due to immunosuppression, desensitization towards tuberculin, subpotent use of tuberculin, and lengthy exposure to a field strain [96]. Steps have been taken to improve specificity by using specific antigens, such as ESAT-6 [101] and a cocktail of ESAT-6/CFP-10/MPB83; however, these studies still need to be validated at a larger scale [5].

Revisiting the animal after 2-3 days application of the TST to check their reaction is labor intensive (and usually impractical for free-ranging wildlife). The alternative IFN$\gamma$ assay is an in vitro blood test based on measuring the CMI response of the animals infected with MB [102]. The IFN- $\gamma$ assay is usually performed using PPD as antigen, although recent studies have evaluated ESAT-6 and CFP10 [103-106]. A problem with the IFN- $\gamma$ assay is that it is a costly process that requires well-trained personnel to carry out the test $[26,107]$. Bacteriological culture of clinical samples (i.e., milk, blood, nasal swab, and cattle tissues) is considered to be the gold standard for bTB diagnosis but, the test requires a minimum of several weeks $[96,108]$. Nucleic acid amplification methods (e.g., PCR) have been also used for bTB diagnosis, but these methods are costly, less sensitive than the bacteriological culture test and again require a trained technician to perform the test $[96,108-$ $110]$.

3.3. Humoral Immune-Response-Based Testing. Another type of immunological test is based on detection of humoral immune response (i.e., antibody production). The major advantages of the antibody-detection tests are that they are inexpensive and relatively easy to perform. However, low sensitivity of the antibody-detection tests remains a concern. Several attempts have been made to develop ELISA tests for detection of antibody response against $\mathrm{MB}$ infections. PPD was used as an antigen to measure antibody response in animals with $\mathrm{MB}$ infection [111, 112], but the cross reactivity of $\mathrm{PPD}$ with closely related mycobacterial species has always been a concern. Auer [113] used a sonicated preparation of $\mathrm{MB}$ as antigen and reported low specificity [113]. Further studies used a specific protein isolated from MB bacillus Calmette-Guerin (BCG) strain, MPB70, as an antigen for developing assays for the diagnosis of bTB. The use of MPB70 achieved better specificity (96.4\%) but had poor sensitivity (18.1\%) [114-116]. Ag85 complex consists of the major secretion products of $\mathrm{MB}$ BCG strain and has 3 major components: $85 \mathrm{~A}(31 \mathrm{kDa}), 85 \mathrm{~B}(30 \mathrm{kDa})$, and $85 \mathrm{C}(31.5 \mathrm{kDa})$. This complex is strongly immunogenic and has been used for the development of assays to diagnose TB and bTB. However, low sensitivity was reported from studies using Ag85 in ELISA format and attributed to falsepositive reactions caused by infections with environmental mycobacteria [54, 81, 115]. MPB83 has been used as antigen in many studies and is a very promising candidate for bTB serodiagnosis [53]. As discussed in the TB section, LAM, ESAT-6, and CFP-10 have also been used as antigens to detect antibody response against MB [117-122]. Further, as molecular biology tools have improved, recombinant proteins have come to be used as antigens for diagnosis of bTB. Since recombinant proteins can be produced at large scale, they are cost-effective and provide consistency in their quality as diagnostic antigen $[55,123,124]$. 
3.4. Point-of-Care Diagnosis and Future Directions. One of the promising antibody-based detection assays, MultiAntigen Print Immuno-Assay (MAPIA), is based on immobilization of antigens onto nitrocellulose membranes by semiautomated microspraying, followed by standard chromogenic immune development. This serodiagnostic test uses a cocktail of multi-antigens, such as MPB83/70, ESAT-6, and CFP10 [36]. In a recent study, seroreactivity with MPB83 in deer was $89 \%$; however, MAPIA showed that $26 \%$ of these were false positives [37]. Based on these MAPIA results, a new version of an immunochromatographic test format for rapid diagnosis of $\mathrm{MB}$ infection, called rapid test (RT), was developed using colloidal gold conjugated to protein A. RT uses recombinant proteins of MPB83 and TBF10 printed onto a membrane either separately as two bands or as a combination of the two antigens in one test line [56]. Diagnostic sensitivity of the RT in experimentally infected deer was $79 \%$, whereas that in naturally infected deer was $67 \%$ [37]. Jaroso et al., [125] compared the RT with the comparative cervical skin test (CCT) and found similar sensitivities of $80.1 \%$. They also found that by combining the results from both RT and CCT, the sensitivity was $100 \%$. It was suggested that the combined uses of RT and CCT would maximize sensitivity of bTB detection [125]. Some recent studies have concluded that ESAT- 6 and CFP10 (used either individually or as cocktail) are better candidates for diagnosis of bTB [126-128].

MAPIA and RT can be conducted in field situations and so can contribute to effective testing/control of bTB, especially in wild animals. However, interpretation of the test results in MAPIA and RT relies on observation of color development on a strip, which may vary depending on examiners. Higher accuracy and consistency could be achieved via a lab-free diagnostic device that outputs numerical data based on level of antibody binding to MB antigen(s). Further, as we discussed above, effort needs to be directed towards identifying a better antigen (or a combination of antigens) to further improve diagnostic sensitivity and specificity.

\section{Johne's Disease}

4.1. Background. Johne's disease (JD) or paratuberculosis is a chronic infectious enteritis of domestic and wild ruminants, causing reduction in milk production, malnutrition, weight loss, and eventually death $[129,130]$. JD is prevalent worldwide and has a significant impact on global animal husbandry. In the USA, the causative agent of JD, Mycobacterium avium subsp. paratuberculosis (MAP), is found in $68 \%$ of dairies [8], with average herd-level prevalence of JD estimated to be $22 \%$. The annual loss in the US dairy industry caused by MAP infection has been estimated at $\$ 220$ million [9]. Economic losses associated with JD arise from decreased milk production, reduced fertility, and higher rate of culling [131]. In addition to the economic impact of JD to dairy industry, it is possible that MAP plays a role in Crohn's disease, which is an inflammatory bowel disease in humans [132]. These economic and possible health concerns create an urgent need for improved control of JD. As no practical treatment is available for JD, a better understanding of the transmission, detection, and management of the disease are the recommended procedures for its control [133].

\subsection{Bacterial Culture and Cell-Mediated Immune-Response-} Based Testing. Diagnostic tests to detect infection with MAP can be categorized as those that identify the organism and those that identify the immunological response to the organism. Fecal culturing for MAP using Herrold's egg yolk medium (HEYM) has been considered as a gold-standard test for JD diagnosis; however, it takes as long as 16 weeks to see an observable growth. Other approaches, such as the use of BACTEC radiometric liquid culture $[134,135]$ and MGIT culture medium [136], have been examined to reduce the culture time but these approaches require a specialist and are relatively expensive. Polymerase-chain-reaction- (PCR) based diagnosis using IS900 insertion sequence [137], HspX [138], or F57 DNA fragment [139], on the feces of suspect animals can also be used. This PCR-based approach is much faster but is less sensitive than the culture test because PCR reaction can be inhibited by substances in the feces. Animals develop both CMI and humoral responses against MAP. A CMI-based diagnostic test, the IFN- $\gamma$ assay, has been evaluated using blood samples of experimentally infected cattle. The study demonstrated that the IFN- $\gamma$ assay could detect MAP infections in early stage of JD [140, 141]; however, IFN- $\gamma$ assay is affected by antigen stimulation and blood sampling-storage conditions [142, 143]. This suggests that the IFN- $\gamma$ test requires further optimization.

4.3. Humoral Immune-Response-Based Testing. Three different tests are used to measure antibody response in JD: complement fixation, agar gel immunodiffusion, and ELISA. The complement fixation and agar gel immunodiffusion tests both suffer poor sensitivity [144], and so a recent report has suggested that ELISAs are the best of the three methods for controlling JD in dairy and beef herds [133]. Diagnoses of JD using ELISA have been reported in many previous studies using different antigens [28, 29, 48, 63, 141, 145-151]. The antigens used in these studies have used protoplasmic antigen (PPA) $[28,29,146,147,149,150]$, lipoarabinomannan (LAM) [48], culture filtrate of MAP [63], and MAP proteins-1152 and 1156 [151] for testing antibodies against MAP. Beam et al. described a crude antigen mixture termed PPA, which is prepared by thorough physical disruption of mycobacterial bacilli followed by removal of cell debris and cell wall components [152]. Although many investigators have prepared PPA using various preparation protocols, it contains proteins very similar to proteins commonly found in closely related mycobacteria species. LAM is one of the components of the cell wall of mycobacteria species [120], and its core structure is shared among mycobacterial species [153].

Sweeney et al. tested milk and serum samples in an LAM-based ELISA to detect antibodies for JD diagnosis and found that sensitivity and specificity of the ELISA were similar regardless of the tested samples (i.e., milk and serum) [48]. McKenna et al. [49] compared diagnostic performance of PPA-based ELISA and LAM-based ELISA using fecal 
culture test as a gold standard. Sensitivity and specificity of the PPA-based ELISA were higher than that for the LAMELISA [49]. PPA and LAM both contain structures common in mycobacterial species, so the use of these molecules as diagnostic antigen can cause false-positive reactions in animals infected with environmental mycobacteria other than MAP [154].

Bannantine et al. tested 18 purified recombinant proteins in ELISA format for serodiagnosis of ovine paratuberculosis. They found that MAP proteins 0862 and 3786 demonstrated the strongest antibody response and MAP protein $2116 \mathrm{c}$ the weakest [58]. Shin et al. used culture filtrate of an MAP strain, JTC, in ELISA format for JD diagnosis and named the method JTC-ELISA [63]. JTC-ELISA showed significantly higher sensitivity $(56.3 \%)$ than that of commercial ELISA tests $(28-44 \%)$ and performed effectively on both serum and milk samples. As mentioned above, the recommended control measure for JD is testing herds by ELISA methods but the current ELISA tests have low sensitivity (28-44.5\%) [29]. We have previously reported that the surface antigens of MAP are capable of detecting anti-MAP antibodies in serum at early stages of JD $[59,60]$. Since mycobacteria are known to express species-specific lipidic molecules on their surface, surface antigens were extracted by gently mixing MAP with various organic solutions and tested for antibody binding in ELISA format [61]. Antigens extracted from MAP by using $80 \%$ ethanol showed the greatest differentiation between antibody binding in JD-negative and JD-positive serum samples [61]. An ELISA test developed using the ethanol extract has been named ethanol vortex ELISA (EVELISA). The results from EVELISA showed that $98.4 \%$ of the JDpositive samples had higher antibody binding levels than those of JD-negative samples, whereas the percentage of positive antibody binding in a commercial ELISA test was $50 \%$ [61]. By using thin layer chromatography, speciesspecific lipidic molecules were detected in the ethanol extract (unpublished data). Eckstein et al. reported that speciesspecific antigenic lipopeptides (e.g., Para-LP-01) exist on the surface of MAP [155], and the high sensitivity of the EVELISA may be attributed to these lipopeptides.

ELISA, as well as other methods for JD diagnosis, needs to be conducted in diagnostic laboratories employing staff with expertise in microbiology, molecular biology, and immunology. This requires a labor-intensive process involving collecting samples into proper containers, indexing, packing, and shipping. Furthermore, cost per sample is relatively high-testing a sample by current fecal culture, PCR, and ELISA tests cost \$16-19, \$25, and \$56 , respectively, and this does not include costs associated with site visits and sample collections and shipping [133]. Because of the labor and cost for the current JD diagnosis, screening of cattle herds for JD is generally conducted at an interval of 6-12 months. During this interval, nonshedding animals can become shedders and low-shedding animals can become high shedders, thereby spreading MAP infection widely in the herd. This relatively long time interval between JD screening tests, in combination with low sensitivity of current diagnostic tests, may have been a reason that MAP infections remain so widespread in the US dairy and beef industries.

4.4. Point-of-Care Diagnosis and Future Directions. Controlling JD requires a better understanding of the spread of MAP in a dairy herd, which can be achieved by continuous monitoring of the infection using a lab-free diagnostic device. For development of a lab-free diagnostic device, microfluidic technology has begun to be employed in the last decade [15]. Microfluidic devices are state-of-the-art tools for biochemical and immunological analysis that have high sensitivity, require only short periods of time, small amounts of reagents, and do not require an expert operator $[13,14,156]$. In our recent study, we developed a prototype of lab-free diagnostic device for JD by using a microfluidic technology and the antigen used in the EVELISA test [157]. The device is composed of microfluidic channels/chamber with electrodes, light source for fluorescence excitation, and light detector. The EVELISA antigen was immobilized in the microchannel and reacted sequentially with bovine serum sample and fluorescently labeled secondary antibody. Liquid flow was controlled by applying AC signals to the electrodes in the microchannel. Further, antibody-antigen interaction was accelerated by creating liquid vortices by applying AC signals to the reaction chamber. The major advantages of this system are its low cost, ultraportable, and disposable immunoreactions chip, and the ability to detect antibodies within $20 \mathrm{~min}$ [157].

\section{Conclusion}

Among the diagnostic methods used for TB, bTB, and JD, serological methods have some compelling advantages that include short turn-around time, simple procedure, and low cost. However, as summarized in Table 1, previous reports on serodiagnosis indicated a lack of diagnostic accuracy and/or insufficient-tested samples for validation of the estimated diagnostic accuracy. The low diagnostic accuracy of the current serodiagnosis for the mycobacterial infections may be due to the false-positive reactions (causing low specificity), arising from exposure of some tested individuals to other nonpathogenic environmental bacteria. Recent studies have indicated that the use of multiple species-specific antigens may improve diagnostic accuracy of the serodiagnosis of the mycobacterial diseases. Some nonprotein molecules (cord factor and lipoarabinomannan) were also evaluated for serodiagnosis of mycobacterial infections. Since mycobacteria are known to produce a variety of species-specific non-protein molecules, further efforts to identify non-protein diagnostic antigens may be a useful contribution to the development of more specific tests for TB, $\mathrm{bTB}$, and JD.

Most, if not all, of the current diagnostic tests for mycobacterial infections are carried out in a diagnostic laboratory, causing cost for sample processing and/or long turn-around time. Lab-free diagnostic devices would be valuable in understanding the epidemiology of the mycobacterial infections and would facilitate their control. The emergence of new technology, microfluidic lab-on-achip (LOC), holds considerable promise for accelerating 
TABLE 1: Summary of humoral immune response based assays.

\begin{tabular}{|c|c|c|c|c|c|c|c|c|}
\hline Target antigen & MTB/MB/MAP & Method of testing & $\mathrm{Se}(\%)$ & Sp (\%) & $P$ & $N$ & Species tested & Reference \\
\hline PPD & MTB & ELISA & 89 & 87 & 18 & 83 & Human & {$[24,25]$} \\
\hline PPD & $\mathrm{MB}$ & ELISA & $68-95$ & $96-99$ & 120 & 223 & Cattle & {$[26,27]$} \\
\hline PPD & MAP & ELISA & $29-72$ & 99 & 359 & 2094 & Cattle & {$[28,29]$} \\
\hline Antigen $5(38 \mathrm{kDa})$ & MTB & ELISA & 89 & $94-100$ & 82 & 30 & Human & {$[30,31]$} \\
\hline Cord factor & MTB & ELISA & $81-84$ & $96-100$ & 65 & 66 & Human & {$[32,33]$} \\
\hline ESAT-6 & MTB & ELISA & 67 & 51 & 100 & 100 & Human & {$[34,35]$} \\
\hline ESAT-6 & $\mathrm{MB}$ & ELISA & $49-59$ & $84-95$ & 522 & 1489 & Cattle & \multirow{2}{*}[36-38]{} \\
\hline ESAT-6 & $\mathrm{MB}$ & MAPIA & 67 & 98 & 9 & 98 & Deer & \\
\hline CFP-10 & MTB & ELISA & $48-63$ & $51-71$ & 100 & 100 & Human & {$[34,39,40]$} \\
\hline CFP-10 & $\mathrm{MB}$ & ELISA & $49-59$ & $84-95$ & 522 & 1489 & Cattle & \multirow{2}{*}[36-38]{} \\
\hline CFP-10 & $\mathrm{MB}$ & MAPIA & 56 & 99 & 9 & 98 & Deer & \\
\hline Kр90 & MTB & ELISA & 78 & 82 & 51 & 71 & Human & {$[41]$} \\
\hline Antigen 60 & MTB & ELISA & $68-91$ & 100 & 337 & 131 & Human & {$[42,43]$} \\
\hline $30 \mathrm{kDa}$ antigen & MTB & ELISA & 84 & 96.7 & 175 & 150 & Human & {$[44,45]$} \\
\hline LAM & MTB & ELISA & 17.8 & 87.7 & 47 & 153 & Human & \multirow{3}{*}[27,46-49]{} \\
\hline LAM & $\mathrm{MB}$ & ELISA & 60 & na & 120 & - & Cattle & \\
\hline LAM & MAP & ELISA & 66 & 88 & 167 & 216 & Cattle & \\
\hline MS & MTB & ELISA & $73-75$ & $97-98$ & 35 & 17 & Human & {$[50-52]$} \\
\hline MPT51 & MTB & ELISA & 80 & na & 53 & - & Human & {$[51]$} \\
\hline MPB70 & $\mathrm{MB}$ & ELISA & 73 & 88 & 120 & 223 & Cattle & \multirow{2}{*}[27,36-38,53]{} \\
\hline MPB70 & $\mathrm{MB}$ & MAPIA & 44 & 100 & 9 & 98 & Deer & \\
\hline Antigen 85 complex & $\mathrm{MB}$ & ELISA & 48 & 89 & 208 & 54 & Cattle & {$[54,55]$} \\
\hline MPB 83 & $\mathrm{MB}$ & ELISA & $49-59$ & $84-95$ & 522 & 1489 & Cattle & {$[36,53,56]$} \\
\hline MPB83 & $\mathrm{MB}$ & MAPIA & 89 & 99 & 9 & 98 & Deer & \multirow{2}{*}[36-38,53,56,57]{} \\
\hline MPB83 & $\mathrm{MB}$ & RT & 60 & 96 & 25 & 25 & Cattle & \\
\hline $\begin{array}{l}\text { MAP proteins } 0862 \text { and } \\
3786\end{array}$ & MAP & ELISA & 81 & na & 11 & - & Sheep & {$[58]$} \\
\hline Ethanol extract & MAP & ELISA & 97.4 & 100 & 64 & 38 & Cattle & {$[59-62]$} \\
\hline JTC & MAP & ELISA & 56.3 & 99 & 444 & 412 & Cattle & {$[63]$} \\
\hline
\end{tabular}

Se, Sensitivity; Sp, Specificity; $P$, no. of positive samples tested; $N$, no. of negative samples tested.

the development of lab-free diagnostic devices for these mycobacterial infections. LOC refers to miniaturized devices that can perform single or multiple laboratory procedures on a chip with a footprint of only a few inches in size [158]. Various LOCs have been developed for biochemical assays, detection of small particles (cells and bacteria), singlecell analysis, immunoassays, and so forth. Because of its small size and capability of automation, the technology offers opportunities for the development of point-of-care diagnostic devices for various diseases and physiological conditions. In the last decade, LOC technology has been employed for development of antibody detection assays $[159,160]$. The principle of the immunoassay is same as conventional serological tests-detection of antibody binding to immobilized diagnostic antigen. However, whole assay processes (antibody reaction, washing, and detection) are carried out in a microfluidic system (microchannels). Liquid flow in the microchannel is controlled by electric fluid handling, pressure-driven fluid handling, or passive capillary force fluid handling [160]. Detection of antibody binding in LOC is based on either optical or nonoptical detection methods [159]. The most common types of optical detection systems are fluorescence detection and surface plasmon resonance. Fluorescence detection is highly useful technique due to its high sensitivity and the ease of integrating a label to the marker [159]. Surface plasmon resonance technology is based on measurement of the change in plasmon mode due to binding of biomolecules (antibody) to the surface (immobilized antigen) [161]. The nonoptical detection system is based mainly on measurement of change in the electrochemical properties due to molecular interactions on the reaction surface. This approach (i.e., 
a label-free sensor) does not require cumbersome detection system and therefore makes the LOC device relatively small and inexpensive [161]. Although development of lab-free diagnostics for mycobacterial diseases is in its infant stage, a recent study demonstrated the detection of MTB using fluorescent markers $[95,162]$. Also, we recently reported that a prototype of LOC-based system could detect antibodies in JD-positive serum in $20 \mathrm{~min}$ [157]. Further, the system was converted to a label-free system using an electrochemical detection, reducing the detection time to $2 \mathrm{~min}$ (unpublished data).

A combination of species-specific (multi) antigens and LOC technology may lead to development of an accurate on-site (in-field) diagnostic device and thereby contribute to effective control of mycobacterial infections.

\section{Acknowledgments}

Our projects related to this review were supported by a 2011 UT AgResearch and Extension Innovation Grant (S. Eda), a UT Research Foundation Technology Maturation Fund (S. Eda), a UT M-CERV seed grant (S. Eda), NIMBioS support to G. J. Hickling, and a NIMBioS Graduate Research Assistantship (A. Wadhwa).

\section{References}

[1] WHO, Global Tuberculosis Control: WHO report 2010, WHO/ HTM/TB/2010.7, 2010.

[2] K. Weyer, S. Carai, and P. Nunn, "Viewpoint TB diagnostics: what does the world really need?" Journal of Infectious Diseases, vol. 204, supplement 4, pp. S1196-S1202, 2011.

[3] L. M. Parsons, Á. Somoskövi, C. Gutierrez et al., "Laboratory diagnosis of tuberculosis in resource-poor Countries: challenges and opportunities," Clinical Microbiology Reviews, vol. 24, no. 2, pp. 314-350, 2011.

[4] S. H. E. Kaufmann, "Fact and fiction in tuberculosis vaccine research: 10 years later," The Lancet Infectious Diseases, vol. 11, no. 8, pp. 633-640, 2011.

[5] I. Schiller, B. Oesch, H. M. Vordermeier et al., "Bovine tuberculosis: a review of current and emerging diagnostic techniques in view of their relevance for disease control and eradication," Transboundary and Emerging Diseases, vol. 57, no. 4, pp. 205-220, 2010.

[6] M. A. Chambers, "Review of the diagnosis and study of tuberculosis in non-bovine wildlife species using immunological methods," Transboundary and Emerging Diseases, vol. 56, no. 6-7, pp. 215-227, 2009.

[7] R. Miller, J. B. Kaneene, S. M. Schmitt, D. P. Lusch, and S. D. Fitzgerald, "Spatial analysis of Mycobacterium bovis infection in white-tailed deer (Odocoileus virginianus) in Michigan, USA," Preventive Veterinary Medicine, vol. 82, no. 1-2, pp. 111-122, 2007.

[8] USDA, "Johne's disease on U. S. dairies USDA APHIS VS National Animal Health Monitoring system," Fort Collins Colo, USA, 1991-2007(No. 521.0408), 2008.

[9] S. L. Ott, S. J. Wells, and B. A. Wagner, "Herd-level economic losses associated with Johne's disease on US dairy operations," Preventive Veterinary Medicine, vol. 40, no. 3-4, pp. 179-192, 1999.
[10] C. Dye and B. G. Williams, "The population dynamics and control of tuberculosis," Science, vol. 328 , no. 5980, pp. 856861, 2010.

[11] A. L. Michel, B. Müller, and P. D. van Helden, "Mycobacterium bovis at the animal-human interface: a problem, or not?" Veterinary Microbiology, vol. 140, no. 3-4, pp. 371-381, 2010.

[12] S. L. B. McKenna, G. P. Keefe, A. Tiwari, J. VanLeeuwen, and H. W. Barkema, "Johne's disease in Canada Part II: disease impacts, risk factors, and control programs for dairy producers," Canadian Veterinary Journal, vol. 47, no. 11, pp. 10891099, 2006.

[13] P. Yager, T. Edwards, E. Fu et al., "Microfluidic diagnostic technologies for global public health," Nature, vol. 442, no. 7101, pp. 412-418, 2006.

[14] E. Fu, P. Yager, P. N. Floriano, N. Christodoulides, and J. T. McDevitt, "Perspective on diagnostics for global health," IEEE Pulse, vol. 2, no. 6, Article ID 6088913, pp. 40-50, 2011.

[15] R. W. Peeling and D. Mabey, "Point-of-care tests for diagnosing infections in the developing world," Clinical Microbiology and Infection, vol. 16, no. 8, pp. 1062-1069, 2010.

[16] J. Dinnes, J. Deeks, H. Kunst et al., "A systematic review of rapid diagnostic tests for the detection of tuberculosis infection," Health Technology Assessment, vol. 11, no. 3, pp. 1-196, 2007.

[17] B. Furlow, "Tuberculosis: a review and update," Radiologic technology, vol. 82, no. 1, pp. 33-52, 2010.

[18] D. B. Young, H. P. Gideon, and R. J. Wilkinson, "Eliminating latent tuberculosis," Trends in Microbiology, vol. 17, no. 5, pp. 183-188, 2009.

[19] W. Sougakoff, "Molecular epidemiology of multidrugresistant strains of Mycobacterium tuberculosis," Clinical Microbiology and Infection, vol. 17, no. 6, pp. 800-805, 2011.

[20] P. A. LoBue, D. A. Enarson, and T. C. Thoen, "Tuberculosis in humans and its epidemiology, diagnosis and treatment in the United States," International Journal of Tuberculosis and Lung Disease, vol. 14, no. 10, pp. 1226-1232, 2010.

[21] J. Rylance, M. Pai, C. Lienhardt, and P. Garner, "Priorities for tuberculosis research: a systematic review," The Lancet Infectious Diseases, vol. 10, no. 12, pp. 886-892, 2010.

[22] M. Pai, A. Ramsay, and R. O’Brien, "Evidence-based tuberculosis diagnosis," PLoS Medicine, vol. 5, no. 7, article e156, 2008.

[23] V. O. Kasprowicz, G. Churchyard, S. D. Lawn, S. B. Squire, and A. Lalvani, "Diagnosing latent tuberculosis in high-risk individuals: rising to the challenge in high-burden areas," Journal of Infectious Diseases, vol. 204, supplement 4, pp. S1168-S1178, 2011.

[24] M. D. Perkins, M. B. Conde, M. Martins, and A. L. Kritski, "Serologic diagnosis of tuberculosis using a simple commercial multiantigen assay," Chest, vol. 123, no. 1, pp. 107-112, 2003.

[25] S. B. Kalish, R. C. Radin, and J. P. Phair, "Use of an enzymelinked immunosorbent assay technique in the differential diagnosis of active pulmonary tuberculosis in humans," Journal of Infectious Diseases, vol. 147, no. 3, pp. 523-530, 1983.

[26] B. M. Buddle, P. G. Livingstone, and G. W. de Lisle, "Advances in ante-mortem diagnosis of tuberculosis in cattle," New Zealand Veterinary Journal, vol. 57, no. 4, pp. 173-180, 2009.

[27] J. Hernández De Anda, M. Monaghan, J. D. Collins, P. J. Brennan, and M. D. Salman, "Evaluation of MPB70, bovine 
PPD and lipoarabinomannan as antigens in ELISA for the serodiagnosis of bovine tuberculosis," Preventive Veterinary Medicine, vol. 27, no. 3-4, pp. 211-215, 1996.

[28] J. Klausen, A. Huda, L. Ekeroth, and P. Ahrens, "Evaluation of serum and milk ELISAs for paratuberculosis in Danish dairy cattle," Preventive Veterinary Medicine, vol. 58, no. 3-4, pp. 171-178, 2003.

[29] M. T. Collins, S. J. Wells, K. R. Petrini, J. E. Collins, R. D. Schultz, and R. H. Whitlock, "Evaluation of five antibody detection tests for diagnosis of bovine paratuberculosis," Clinical and Diagnostic Laboratory Immunology, vol. 12, no. 6, pp. 685-692, 2005.

[30] A. B. Andersen and E. B. Hansen, "Structure and mapping of antigenic domains of protein antigen b, a 38,000-molecularweight protein of Mycobacterium tuberculosis," Infection and Immunity, vol. 57, no. 8, pp. 2481-2488, 1989.

[31] Y. Ma, Y. M. Wang, and T. M. Daniel, "Enzyme-linked immunosorbent assay using Mycobacterium tuberculosis antigen 5 for the diagnosis of pulmonary tuberculosis in China," American Review of Respiratory Disease, vol. 134, no. 6, pp. 1273-1275, 1986.

[32] H. He, S. Oka, Y. Han et al., "Rapid serodiagnosis of human mycobacteriosis by ELISA using cord factor (trehalose-6,6'dimycolate) purified from Mycobacterium tuberculosis as antigen," FEMS Microbiology Immunology, vol. 76, no. 4, pp. 201-204, 1991.

[33] R. Maekura, M. Nakagawa, Y. Nakamura et al., "Clinical evaluation of rapid serodiagnosis of pulmonary tuberculosis by ELISA with cord factor (trehalose-6,6'-dimycolate) as antigen purified from Mycobacterium tuberculosis," American Review of Respiratory Disease, vol. 148, no. 4, pp. 997-1001, 1993.

[34] C. Greenaway, C. Lienhardt, R. Adegbola, P. Brusasca, K. McAdam, and D. Menzies, "Humoral response to Mycobacterium tuberculosis antigens in patients with tuberculosis in the Gambia," International Journal of Tuberculosis and Lung Disease, vol. 9, no. 10, pp. 1112-1119, 2005.

[35] H. Zhang, J. Wang, J. Lei et al., "PPE protein (Rv3425) from DNA segment RD11 of Mycobacterium tuberculosis: a potential B-cell antigen used for serological diagnosis to distinguish vaccinated controls from tuberculosis patients," Clinical Microbiology and Infection, vol. 13, no. 2, pp. 139145, 2007.

[36] K. P. Lyashchenko, M. Singh, R. Colangeli, and M. L. Gennaro, "A multi-antigen print immunoassay for the development of serological diagnosis of infectious diseases," Journal of Immunological Methods, vol. 242, no. 1-2, pp. 91-100, 2000.

[37] K. P. Lyashchenko, R. Greenwald, J. Esfandiari et al., "Animalside serologic assay for rapid detection of Mycobacterium bovis infection in multiple species of free-ranging wildlife," Veterinary Microbiology, vol. 132, no. 3-4, pp. 283-292, 2008.

[38] C. Whelan, E. Shuralev, G. O'Keeffe et al., "Multiplex immunoassay for serological diagnosis of Mycobacterium bovis infection in cattle," Clinical and Vaccine Immunology, vol. 15, no. 12, pp. 1834-1838, 2008.

[39] D. C. Dillon, M. R. Alderson, C. H. Day et al., "Molecular and immunological characterization of Mycobacterium tuberculosis CFP-10, an immunodiagnostic antigen missing in Mycobacterium bovis BCG," Journal of Clinical Microbiology, vol. 38, no. 9, pp. 3285-3290, 2000.

[40] M. K. Murthy, R. R. V. Parasa, A. Deenadayalan, P. Sharma, and A. Raja, "Evaluation of the diagnostic potential of region of deletion-1-encoded antigen culture filtrate protein10 in pulmonary tuberculosis," Diagnostic Microbiology and Infectious Disease, vol. 59, no. 3, pp. 295-302, 2007.

[41] S. Arikan, S. Tuncer, D. Us, S. Ünal, and Ş. Ustaçelebi, "Anti$\mathrm{Kp} 90$ IgA antibodies in the diagnosis of active tuberculosis," Chest, vol. 114, no. 5, pp. 1253-1257, 1998.

[42] Y. L. Zou, J. D. Zhang, M. H. Chen, G. Q. Shi, J. Prignot, and C. Cocito, "Serological analysis of pulmonary and extrapulmonary tuberculosis with enzyme-linked immunosorbent assays for anti-A60 immunoglobulins," Clinical Infectious Diseases, vol. 19, no. 6, pp. 1084-1091, 1994.

[43] S. Gupta, S. Kumari, J. N. Banwalikar, and S. K. Gupta, "Diagnostic utility of the estimation of mycobacterial Antigen A60 specific immunoglobulins IgM, IgA and IgG in the sera of cases of adult human tuberculosis," Tubercle and Lung Disease, vol. 76, no. 5, pp. 418-424, 1995.

[44] J. A. McDonough, E. Sada, A. A. Sippola, L. E. Ferguson, and T. M. Daniel, "Microplate and dot immunoassays for the serodiagnosis of tuberculosis," Journal of Laboratory and Clinical Medicine, vol. 120, no. 2, pp. 318-322, 1992.

[45] K. R. Uma Devi, B. Ramalingam, and A. Raja, "Antibody response to Mycobacterium tuberculosis 30 and $16 \mathrm{kDa}$ antigens in pulmonary tuberculosis with human immunodeficiency virus coinfection," Diagnostic Microbiology and Infectious Disease, vol. 46, no. 3, pp. 205-209, 2003.

[46] P. Daley, J. S. Michael, P. Hmar et al., "Blinded evaluation of commercial urinary lipoarabinomannan for active tuberculosis: a pilot study," International Journal of Tuberculosis and Lung Disease, vol. 13, no. 8, pp. 989-995, 2009.

[47] W. R. Waters, M. V. Palmer, and D. L. Whipple, "Mycobacterium bovis-infected white-tailed deer (Odocoileus virginianus): detection of immunoglobulin specific to crude mycobacterial antigens by ELISA," Journal of Veterinary Diagnostic Investigation, vol. 14, no. 6, pp. 470-475, 2002.

[48] R. W. Sweeney, R. H. Whitlock, C. L. Buckley, P. Spencer, A. E. Rosenberger, and L. J. Hutchinson, "Diagnosis of paratuberculosis in dairy cattle, using enzyme-linked immunosorbent assay for detection of antibodies against Mycobacterium paratuberculosis in milk," American Journal of Veterinary Research, vol. 55, no. 7, pp. 905-909, 1994.

[49] S. L. B. McKenna, D. C. Sockett, G. P. Keefe, J. McClure, J. A. VanLeeuwen, and H. W. Barkema, "Comparison of two enzyme-linked immunosorbent assays for diagnosis of Mycobacterium avium subsp. paratuberculosis," Journal of Veterinary Diagnostic Investigation, vol. 17, no. 5, pp. 463466, 2005.

[50] C. V. Smith, C. C. Huang, A. Miczak, D. G. Russell, J. C. Sacchettini, and K. Höner zu Bentrup, "Biochemical and structural studies of malate synthase from Mycobacterium tuberculosis," Journal of Biological Chemistry, vol. 278, no. 3, pp. 1735-1743, 2003.

[51] J. M. Achkar, Y. Dong, R. S. Holzman et al., "Mycobacterium tuberculosis malate synthase- and MPT51-based serodiagnostic assay as an adjunct to rapid identification of pulmonary tuberculosis," Clinical and Vaccine Immunology, vol. 13, no. 11, pp. 1291-1293, 2006.

[52] A. Wanchu, Y. Dong, S. Sethi et al., "Biomarkers for clinical and incipient tuberculosis: performance in a TB-endemic country," PLoS One, vol. 3, no. 4, Article ID e2071, 2008.

[53] H. G. Wiker, "MPB70 and MPB83-major antigens of Mycobacterium bovis," Scandinavian Journal of Immunology, vol. 69, no. 6, pp. 492-499, 2009. 
[54] T. Fifis, J. S. Rothel, and P. R. Wood, "Soluble Mycobacterium bovis protein antigens: studies on their purification and immunological evaluation," Veterinary Microbiology, vol. 40, no. 1-2, pp. 65-81, 1994.

[55] E. B. D. Silva, B. D. D. S. Silva, J. R. R. Leon, A. Kipnis, I. K. F. de Miranda Santos, and A. P. Junqueira-Kipnis, "Using BCG, MPT-51 and Ag85 as antigens in an indirect ELISA for the diagnosis of bovine tuberculosis," Veterinary Journal, vol. 187, no. 2, pp. 276-278, 2011.

[56] R. Greenwald, J. Esfandiari, S. Lesellier et al., "Improved serodetection of Mycobacterium bovis infection in badgers (Meles meles) using multiantigen test formats," Diagnostic Microbiology and Infectious Disease, vol. 46, no. 3, pp. 197203, 2003.

[57] W. R. Waters, M. V. Palmer, T. C. Thacker et al., "Early antibody responses to experimental Mycobacterium bovis infection of cattle," Clinical and Vaccine Immunology, vol. 13, no. 6, pp. 648-654, 2006.

[58] J. P. Bannantine, V. Rosu, S. Zanetti, S. Rocca, N. Ahmed, and L. A. Sechi, "Antigenic profiles of recombinant proteins from Mycobacterium avium subsp. paratuberculosis in sheep with Johne's disease," Veterinary Immunology and Immunopathology, vol. 122, no. 1-2, pp. 116-125, 2008.

[59] S. Eda, B. Elliott, M. C. Scott et al., "New method of serological testing for Mycobacterium avium subsp. paratuberculosis (Johne's disease) by flow cytometry," Foodborne Pathogens and Disease, vol. 2, no. 3, pp. 250-262, 2005.

[60] C. A. Speer, M. C. Scott, J. P. Bannantine et al., "A novel enzyme-linked immunosorbent assay for diagnosis of Mycobacterium avium subsp. paratuberculosis infections (Johne's disease) in cattle," Clinical and Vaccine Immunology, vol. 13, no. 5, pp. 535-540, 2006.

[61] S. Eda, J. P. Bannantine, W. R. Waters et al., "A highly sensitive and subspecies-specific surface antigen enzymelinked immunosorbent assay for diagnosis of Johne's disease," Clinical and Vaccine Immunology, vol. 13, no. 8, pp. 837-844, 2006.

[62] M. C. Scott, J. P. Bannantine, Y. Kaneko et al., "Absorbed EVELISA: a diagnostic test with improved specificity for Johne's disease in cattle," Foodborne Pathogens and Disease, vol. 7, no. 11, pp. 1291-1296, 2010.

[63] S. J. Shin, D. Cho, and M. T. Collins, "Diagnosis of bovine paratuberculosis by a novel enzyme-linked immunosorbent assay based on early secreted antigens of Mycobacterium avium subsp. paratuberculosis," Clinical and Vaccine Immunology, vol. 15, no. 8, pp. 1277-1281, 2008.

[64] WHO, Diagnostics for tuberculosis: global demand and market potential, WHO, Geneva, Switzerland, 2006.

[65] R. Rajeswari, V. Chandrasekaran, M. Suhadev, S. Sivasubramaniam, G. Sudha, and G. Renu, "Factors associated with patient and health system delays in the diagnosis of tuberculosis in South India," International Journal of Tuberculosis and Lung Disease, vol. 6, no. 9, pp. 789-795, 2002.

[66] D. Shingadia and V. Novelli, "Diagnosis and treatment of tuberculosis in children," Lancet Infectious Diseases, vol. 3, no. 10, pp. 624-632, 2003.

[67] J. Minion, A. Zwerling, and M. Pai, "Diagnostics for tuberculosis: what new knowledge did we gain through the International Journal of Tuberculosis and Lung Disease in 2008?" International Journal of Tuberculosis and Lung Disease, vol. 13, no. 6, pp. 691-697, 2009.
[68] B. Kambashi, G. Mbulo, R. McNerney et al., "Utility of nucleic acid amplification techniques for the diagnosis of pulmonary tuberculosis in sub-Saharan Africa," International Journal of Tuberculosis and Lung Disease, vol. 5, no. 4, pp. 364-369, 2001.

[69] M. Pai, L. L. Flores, A. Hubbard, L. W. Riley, and J. M. Colford, "Nucleic acid amplification tests in the diagnosis of tuberculous pleuritis: a systematic review and meta-analysis," BMC Infectious Diseases, vol. 4, article no. 6, 2004.

[70] J. Pouchot, A. Grasland, C. Collet, J. Coste, J. M. Esdaile, and P. Vinceneux, "Reliability of tuberculin skin test measurement," Annals of Internal Medicine, vol. 126, no. 3, pp. 210-214, 1997.

[71] S. Ahmad, "New approaches in the diagnosis and treatment of latent tuberculosis infection," Respiratory Research, vol. 11, article no. 169, 2010.

[72] V. Herrera, S. Perry, J. Parsonnet, and N. Banaei, "Clinical application and limitations of interferon- $\gamma$ release assays for the diagnosis of latent tuberculosis infection," Clinical Infectious Diseases, vol. 52, no. 8, pp. 1031-1037, 2011.

[73] D. W. Connell, M. Berry, G. Cooke, and O. M. Kon, "Update on tuberculosis: TB in the early 21st century," European Respiratory Review, vol. 20, no. 120, pp. 71-84, 2011.

[74] C. M. Denkinger, K. Dheda, and M. Pai, "Guidelines on interferon- $\gamma$ release assays for tuberculosis infection: concordance, discordance or confusion?" Clinical Microbiology and Infection, vol. 17, no. 6, pp. 806-814, 2011.

[75] K. R. Steingart, M. Henry, S. Laal et al., "Commercial serological antibody detection tests for the diagnosis of pulmonary tuberculosis: a systematic review," PLoS Medicine, vol. 4, no. 6, article e202, 2007.

[76] H. C. Teixeira, C. Abramo, and M. E. Munk, "Immunological diagnosis of tuberculosis: problems and strategies for success," Jornal Brasileiro de Pneumologia, vol. 33, no. 3, pp. 323334, 2007.

[77] G. H. Bothamley and R. M. Rudd, "Clinical evaluation of a serological assay using a monoclonal antibody (TB72) to the $38 \mathrm{kDa}$ antigen of Mycobacterium tuberculosis," European Respiratory Journal, vol. 7, no. 2, pp. 240-246, 1994.

[78] R. A. Cole, H. M. Lu, Y. Z. Shi, J. Wang, T. De-Hua, and A. T. Zhou, "Clinical evaluation of a rapid immunochromatographic assay based on the $38 \mathrm{kDa}$ antigen of Mycobacterium tuberculosis on patients with pulmonary tuberculosis in China," Tubercle and Lung Disease, vol. 77, no. 4, pp. 363368, 1996.

[79] S. Kunnath-Velayudhan and M. L. Gennaro, "Immunodiagnosis of tuberculosis: a dynamic view of biomarker discovery," Clinical Microbiology Reviews, vol. 24, no. 4, pp. 792-805, 2011.

[80] E. D. Chan, L. Heifets, and M. D. Iseman, "Immunologic diagnosis of tuberculosis: a review," Tubercle and Lung Disease, vol. 80, no. 3, pp. 131-140, 2000.

[81] H. G. Wiker and M. Harboe, "The antigen 85 complex: a major secretion product of Mycobacterium tuberculosis," Microbiological Reviews, vol. 56, no. 4, pp. 648-661, 1992.

[82] K. R. Steingart, N. Dendukuri, M. Henry et al., "Performance of purified antigens for serodiagnosis of pulmonary tuberculosis: a meta-analysis," Clinical and Vaccine Immunology, vol. 16, no. 2, pp. 260-276, 2009.

[83] C. Cocito and F. Vanlinden, "Preparation and properties of antigen 60 from Mycobacterium bovis BCG," Clinical and Experimental Immunology, vol. 66, no. 2, pp. 262-272, 1986. 
[84] M. Alifano, R. De Pascalis, M. Sofia, S. Faraone, M. Del Pezzo, and I. Covelli, "Detection of IgG and IgA against the mycobacterial antigen A60 in patients with extrapulmonary tuberculosis," Thorax, vol. 53, no. 5, pp. 377-380, 1998.

[85] M. Turneer, E. Van Nerom, J. Nyabenda, A. Waelbroeck, A. Duvivier, and M. Toppet, "Determination of humoral immunoglobulins $\mathrm{M}$ and $\mathrm{G}$ directed against mycobacterial antigen 60 failed to diagnose primary tuberculosis and mycobacterial adenitis in children," American Journal of Respiratory and Critical Care Medicine, vol. 150, no. 6, pp. 1508-1512, 1994.

[86] M. Torres, P. Mendez-Sampeiro, L. Jimenez-Zamudio et al., "Comparison of the immune response against Mycobacterium tuberculosis antigens between a group of patients with active pulmonary tuberculosis and healthy household contacts," Clinical and Experimental Immunology, vol. 96, no. 1, pp. 75-78, 1994.

[87] K. K. Singh, Y. Dong, J. T. Belisle, J. Harder, V. K. Arora, and S. Laal, "Antigens of Mycobacterium tuberculosis recognized by antibodies during incipient, subclinical tuberculosis," Clinical and Diagnostic Laboratory Immunology, vol. 12, no. 2, pp. 354-358, 2005.

[88] S. D. Lawn, D. J. Edwards, K. Kranzer, M. Vogt, L. G. Bekker, and R. Wood, "Urine lipoarabinomannan assay for tuberculosis screening before antiretroviral therapy diagnostic yield and association with immune reconstitution disease," AIDS, vol. 23, no. 14, pp. 1875-1880, 2009.

[89] J. Peter, C. Green, M. Hoelscher, P. Mwaba, A. Zumla, and K. Dheda, "Urine for the diagnosis of tuberculosis: current approaches, clinical applicability, and new developments," Current Opinion in Pulmonary Medicine, vol. 16, no. 3, pp. 262-270, 2010.

[90] WHO, Laboratory-based evaluation of 19 commercially available rapid diagnostic tests for tuberculosis, Special Program for Research and Training in Tropical Diseases. Diagnostics evaluation series, 2, World Health Organization, Geneva, Switzerland, 2008.

[91] A. Wanchu, "Advances in serology for diagnosing TB in the HIV infected," The Indian Journal of Chest Diseases \& Allied Sciences, vol. 47, no. 1, pp. 31-37, 2005.

[92] A. Van Rie, L. Page-Shipp, L. Scott, I. Sanne, and W. Stevens, "Xpert MTB/RIF for point-of-care diagnosis of TB in highHIV burden, resource-limited countries: hype or hope?" Expert Review of Molecular Diagnostics, vol. 10, no. 7, pp. 937-946, 2010.

[93] C. C. Boehme, P. Nabeta, D. Hillemann et al., "Rapid molecular detection of tuberculosis and rifampin resistance," New England Journal of Medicine, vol. 363, no. 11, pp. 1005-1015, 2010.

[94] P. M. Small and M. Pai, "Tuberculosis diagnosis—time for a game change," New England Journal of Medicine, vol. 363, no. 11, pp. 1070-1071, 2010.

[95] R. McNerney and P. Daley, "Towards a point-of-care test for active tuberculosis: obstacles and opportunities," Nature Reviews Microbiology, vol. 9, no. 3, pp. 204-213, 2011.

[96] R. de la Rua-Domenech, A. T. Goodchild, H. M. Vordermeier, R. G. Hewinson, K. H. Christiansen, and R. S. CliftonHadley, "Ante mortem diagnosis of tuberculosis in cattle: a review of the tuberculin tests, $\gamma$-interferon assay and other ancillary diagnostic techniques," Research in Veterinary Science, vol. 81, no. 2, pp. 190-210, 2006.

[97] Anon, "Bovine Tuberculosis. Diagnostic techniques," in Manual of Diagnostic Tests and Vaccines for Terrestrial Animals, chapter 2.4.7, pp. 686-689, OIE, 2008.
[98] J. Francis, R. J. Seiler, and I. W. Wilkie, "The sensitivity and specificity of various tuberculin tests using bovine PPD and other tuberculins," Veterinary Record, vol. 103, no. 19, pp. 420-425, 1978.

[99] L. G. Adams, "In vivo and in vitro diagnosis of Mycobacterium bovis infection," OIE Revue Scientifique et Technique, vol. 20, no. 1, pp. 304-324, 2001.

[100] M. L. Monaghan, M. L. Doherty, J. D. Collins, J. F. Kazda, and P. J. Quinn, "The tuberculin test," Veterinary Microbiology, vol. 40, no. 1-2, pp. 111-124, 1994.

[101] J. M. Pollock, J. McNair, H. Bassett et al., "Specific delayed-type hypersensitivity responses to ESAT-6 identify tuberculosis-infected cattle," Journal of Clinical Microbiology, vol. 41, no. 5, pp. 1856-1860, 2003.

[102] P. R. Wood and S. L. Jones, "BOVIGAM: an in vitro cellular diagnostic test for bovine tuberculosis," Tuberculosis, vol. 81, no. 1-2, pp. 147-155, 2001.

[103] H. M. Vordermeier, P. C. Cockle, A. Whelan et al., "Development of diagnostic reagents to differentiate between Mycobacterium bovis BCG vaccination and M. bovis infection in cattle," Clinical and Diagnostic Laboratory Immunology, vol. 6, no. 5, pp. 675-682, 1999.

[104] C. Aagaard, M. Govaerts, V. Meikle et al., "Optimizing antigen cocktails for detection of Mycobacterium bovis in herds with different prevalences of bovine tuberculosis: ESAT6CFP10 mixture shows optimal sensitivity and specificity," Journal of Clinical Microbiology, vol. 44, no. 12, pp. 43264335, 2006.

[105] M. V. Palmer, W. R. Waters, T. C. Thacker, R. Greenwald, J. Esfandiari, and K. P. Lyashchenko, "Effects of different tuberculin skin-testing regimens on gamma interferon and antibody responses in cattle experimentally infected with Mycobacterium bovis," Clinical and Vaccine Immunology, vol. 13, no. 3, pp. 387-394, 2006.

[106] H. M. Vordermeier, A. Whelan, P. J. Cockle, L. Farrant, N. Palmer, and R. G. Hewinson, "Use of synthetic peptides derived from the antigens ESAT- 6 and CFP-10 for differential diagnosis of bovine tuberculosis in cattle," Clinical and Diagnostic Laboratory Immunology, vol. 8, no. 3, pp. 571-578, 2001.

[107] D. Dalley, M. A. Chambers, P. Cockle, W. Pressling, D. Gavier-Widén, and R. G. Hewinson, "A lymphocyte transformation assay for the detection of Mycobacterium bovis infection in the Eurasian Badger (Meles meles)," Veterinary Immunology and Immunopathology, vol. 70, no. 1-2, pp. 8594, 1999.

[108] M. J. Taylor, M. S. Hughes, R. A. Skuce, and S. D. Neill, "Detection of Mycobacterium bovis in bovine clinical specimens using real-time fluorescence and fluorescence resonance energy transfer probe rapid-cycle PCR," Journal of Clinical Microbiology, vol. 39, no. 4, pp. 1272-1278, 2001.

[109] F. Vitale, G. Capra, L. Maxia, S. Reale, G. Vesco, and S. Caracappa, "Detection of Mycobacterium tuberculosis complex in cattle by PCR using milk, lymph node aspirates, and nasal swabs," Journal of Clinical Microbiology, vol. 36, no. 4, pp. 1050-1055, 1998.

[110] E. R. Travis, W. H. Gaze, A. Pontiroli et al., "An InterLaboratory validation of a real time PCR assay to measure host excretion of bacterial pathogens, particularly of Mycobacterium bovis," PLoS One, vol. 6, no. 11, Article ID e27369, 2011.

[111] C. A. Thoen, M. R. Hall, A. Tannis, B. S. Petersburg, and R. Harrington, "Detection of mycobacterial antibodies in 
sera of cattle experimentally exposed to Mycobacterium bovis by use of a modified enzyme linked immunosorbent assay," in Proceedings of the 26th Annual Meeting of the American Association of Veterinary Laboratory Diagnosticians, pp. 2538, Las Vegas, Nev, USA, October 1983.

[112] W. Lilenbaum, E. R. Ribeiro, G. N. Souza et al., "Evaluation of an ELISA-PPD for the diagnosis of bovine tuberculosis in field trials in Brazil," Research in Veterinary Science, vol. 66, no. 3, pp. 191-195, 1999.

[113] L. A. Auer, "Assessment of an enzyme linked immunosorbent assay for the detection of cattle infected with Mycobacterium bovis," Australian veterinary journal, vol. 64, no. 6, pp. 172176, 1987.

[114] T. Fifis, P. Plackett, L. A. Corner, and P. R. Wood, "Purification of a major Mycobacterium bovis antigen for the diagnosis of bovine tuberculosis," Scandinavian Journal of Immunology, vol. 29, no. 1, pp. 91-101, 1989.

[115] M. Harboe, H. G. Wiker, J. R. Duncan et al., "Protein Gbased enzyme-linked immunosorbent assay for anti-MPB70 antibodies in bovine tuberculosis," Journal of Clinical Microbiology, vol. 28, no. 5, pp. 913-921, 1990.

[116] P. R. Wood, L. A. Corner, J. S. Rothel et al., "A field evaluation of serological and cellular diagnostic tests for bovine tuberculosis," Veterinary Microbiology, vol. 31, no. 1, pp. 71-79, 1992.

[117] C. M. Gaborick, M. D. Salman, R. P. Ellis, and J. Triantis, "Evaluation of a five-antigen ELISA for diagnosis of tuberculosis in cattle and Cervidae," Journal of the American Veterinary Medical Association, vol. 209, no. 5, pp. 962-966, 1996.

[118] A. P. Koets, V. P. M. G. Rutten, M. De Boer, D. Bakker, P. Valentin-Weigand, and W. Van Eden, "Differential changes in heat shock protein-, lipoarabinomannan-, and purified protein derivative-specific immunoglobulin G1 and G2 isotype responses during bovine Mycobacterium avium subsp. paratuberculosis infection," Infection and Immunity, vol. 69, no. 3, pp. 1492-1498, 2001.

[119] R. A. Miller, S. Dissanayake, and T. M. Buchanan, "Development of an enzyme-linked immunosorbent assay using arabinomannan from Mycobacterium smegmatis: a potentially useful screening test for the diagnosis of incubating leprosy," American Journal of Tropical Medicine and Hygiene, vol. 32, no. 3, pp. 555-564, 1983.

[120] E. A. Sugden, K. Stilwell, and A. Michaelides, "A comparison of lipoarabinomannan with other antigens used in absorbed enzyme immunoassays for the serological detection of cattle infected with Mycobacterium paratuberculosis," Journal of Veterinary Diagnostic Investigation, vol. 9, no. 4, pp. 413-417, 1997.

[121] K. Lyashchenko, C. Manca, R. Colangeli, A. Heijbel, A. Williams, and M. L. Gennaro, "Use of Mycobacterium tuberculosis complex-specific antigen cocktails for a skin test specific for tuberculosis," Infection and Immunity, vol. 66, no. 8, pp. 3606-3610, 1998.

[122] K. Lyashchenko, A. O. Whelan, R. Greenwald et al., "Association of tuberculin-boosted antibody responses with pathology and cell-mediated immunity in cattle vaccinated with Mycobacterium bovis BCG and infected with M. bovis," Infection and Immunity, vol. 72, no. 5, pp. 2462-2467, 2004.

[123] M. Amadori, K. P. Lyashchenko, M. L. Gennaro, J. M. Pollock, and I. Zerbini, "Use of recombinant proteins in antibody tests for bovine tuberculosis," Veterinary Microbiology, vol. 85, no. 4, pp. 379-389, 2002.
[124] H. C. Koo, Y. H. Park, J. Ahn et al., "Use of rMPB70 protein and ESAT-6 peptide as antigens for comparison of the enzyme-linked immunosorbent, immunochromatographic, and latex bead agglutination assays for serodiagnosis of bovine tuberculosis," Journal of Clinical Microbiology, vol. 43, no. 9, pp. 4498-4506, 2005.

[125] R. Jaroso, J. Vicente, M. P. Martín-Hernando et al., "Antemortem testing wild fallow deer for bovine tuberculosis," Veterinary Microbiology, vol. 146, no. 3-4, pp. 285-289, 2010.

[126] M. Vordermeier, S. V. Gordon, and R. G. Hewinson, "Mycobacterium bovis antigens for the differential diagnosis of vaccinated and infected cattle," Veterinary Microbiology, vol. 151, no. 1-2, pp. 8-13, 2011.

[127] H. M. Vordermeier, S. G. Rhodes, G. Dean et al., "Cellular immune responses induced in cattle by heterologous primeboost vaccination using recombinant viruses and bacille Calmette-Guérin,” Immunology, vol. 112, no. 3, pp. 461-470, 2004.

[128] M. V. Palmer and W. R. Waters, "Advances in bovine tuberculosis diagnosis and pathogenesis: what policy makers need to know," Veterinary Microbiology, vol. 112, no. 2-4, pp. 181190, 2006.

[129] C. Cocito, P. Gilot, M. Coene, M. De Kesel, P. Poupart, and P. Vannuffel, "Paratuberculosis," Clinical Microbiology Reviews, vol. 7, no. 3, pp. 328-345, 1994.

[130] J. R. Stabel, “Johne's disease: a hidden threat," Journal of Dairy Science, vol. 81, no. 1, pp. 283-288, 1998.

[131] K. V. Nordlund, W. J. Goodger, J. Pelletier, and M. T. Collins, "Associations between subclinical paratuberculosis and milk production, milk components, and somatic cell counts in dairy herds," Journal of the American Veterinary Medical Association, vol. 208, no. 11, pp. 1872-1876, 1996.

[132] J. W. Wynne, T. J. Bull, T. Seemann et al., "Exploring the zoonotic potential of Mycobacterium avium subspecies paratuberculosis through comparative genomics," PLoS One, vol. 6, no. 7, Article ID e22171, 2011.

[133] M. T. Collins, I. A. Gardner, F. B. Garry, A. J. Roussel, and S. J. Wells, "Consensus recommendations on diagnostic testing for the detection of paratuberculosis in cattle in the United States," Journal of the American Veterinary Medical Association, vol. 229, no. 12, pp. 1912-1919, 2006.

[134] D. V. Cousins, R. J. Evans, and B. R. Francis, "Use of BACTEC radiometric culture method and polymerase chain reaction for the rapid screening of faeces and tissues for Mycobacterium paratuberculosis," Australian Veterinary Journal, vol. 72, no. 12, pp. 458-462, 1995.

[135] R. J. Whittington, I. Marsh, S. Mcallister, M. J. Turner, D. J. Marshall, and C. A. Fraser, "Evaluation of modified BACTEC 12B radiometric medium and solid media for culture of Mycobacterium avium subsp. paratuberculosis from sheep," Journal of Clinical Microbiology, vol. 37, no. 4, pp. 1077-1083, 1999.

[136] S. Gumber and R. J. Whittington, "Comparison of BACTEC 460 and MGIT 960 systems for the culture of Mycobacterium avium subsp. paratuberculosis S strain and observations on the effect of inclusion of ampicillin in culture media to reduce contamination," Veterinary Microbiology, vol. 119, no. 1, pp. 42-52, 2007.

[137] T. J. Bull, J. Hermon-Taylor, I. Pavlik, F. El-Zaatari, and M. Tizard, "Erratum: Characterization of IS900 loci in Mycobacterium avium subsp. paratuberculosis and development of multiplex PCR typing," Microbiology, vol. 146, no. 12, p. 3285, 2000. 
[138] J. L. E. Ellingson, C. A. Bolin, and J. R. Stabel, "Identification of a gene unique to Mycobacterium avium subspecies paratuberculosis and application to diagnosis of paratuberculosis," Molecular and Cellular Probes, vol. 12, no. 3, pp. 133-142, 1998.

[139] P. Poupart, M. Coene, H. Van Heuverswyn, and C. Cocito, "Preparation of a specific RNA probe for detection of Mycobacterium paratuberculosis and diagnosis of Johne's disease," Journal of Clinical Microbiology, vol. 31, no. 6, pp. 1601-1605, 1993.

[140] A. Huda, P. Lind, A. B. Christoffersen, and G. Jungersen, "Analysis of repeated tests for interferon-gamma (IFN- $\gamma$ ) response and faecal excretion for diagnosis of subclinical paratuberculosis in Danish cattle," Veterinary Immunology and Immunopathology, vol. 94, no. 3-4, pp. 95-103, 2003.

[141] A. Huda, G. Jungersen, and P. Lind, "Longitudinal study of interferon-gamma, serum antibody and milk antibody responses in cattle infected with Mycobacterium avium subsp. paratuberculosis," Veterinary Microbiology, vol. 104, no. 1-2, pp. 43-53, 2004.

[142] K. L. Bosward, N. K. Dhand, D. J. Begg, P. C. Thomson, D. L. Emery, and R. J. Whittington, "Optimization of a whole blood gamma interferon assay for the detection of sheep infected with Mycobacterium avium subspecies paratuberculosis," Journal of Veterinary Diagnostic Investigation, vol. 22, no. 2, pp. 210-217, 2010.

[143] V. J. Timms, M. M. Gehringer, H. M. Mitchell, G. Daskalopoulos, and B. A. Neilan, "How accurately can we detect Mycobacterium avium subsp. paratuberculosis infection?" Journal of Microbiological Methods, vol. 85, no. 1, pp. $1-8,2011$.

[144] D. M. Sherman, J. M. Gay, D. S. Bouley, and G. H. Nelson, "Comparison of the complement-fixation and agar gel immunodiffusion tests for diagnosis of subclinical bovine paratuberculosis," American journal of veterinary research, vol. 51, no. 3, pp. 461-465, 1990.

[145] S. S. Nielsen, Y. T. Gröhn, and C. Enevoldsen, "Variation of the milk antibody response to paratuberculosis in naturally infected dairy cows," Journal of Dairy Science, vol. 85, no. 11, pp. 2795-2802, 2002.

[146] S. Hendrick, T. Duffield, K. Leslie, K. Lissemore, M. Archambault, and D. Kelton, "The prevalence of mild and serum antibodies to Mycobacterium avium subspecies paratuberculosis in dairy herds in Ontario," Canadian Veterinary Journal, vol. 46, no. 12, pp. 1126-1129, 2005.

[147] S. J. Wells, M. T. Collins, K. S. Faaberg et al., "Evaluation of a rapid fecal PCR test for detection of Mycobacterium avium subsp. paratuberculosis in dairy cattle," Clinical and Vaccine Immunology, vol. 13, no. 10, pp. 1125-1130, 2006.

[148] H. van Weering, G. van Schaik, A. van der Meulen, M. Waal, P. Franken, and K. van Maanen, "Diagnostic performance of the Pourquier ELISA for detection of antibodies against Mycobacterium avium subspecies paratuberculosis in individual milk and bulk milk samples of dairy herds," Veterinary Microbiology, vol. 125, no. 1-2, pp. 49-58, 2007.

[149] S. V. Singh, A. V. Singh, R. Singh et al., "Evaluation of highly sensitive indigenous milk ELISA kit with fecal culture, milk culture and fecal-PCR for the diagnosis of bovine Johne's disease (BJD) in India," Comparative Immunology, Microbiology and Infectious Diseases, vol. 30, no. 3, pp. 175186, 2007.

[150] G. Sharma, S. V. Singh, I. Sevilla et al., "Evaluation of indigenous milk ELISA with $\mathrm{m}$-culture and $\mathrm{m}$-PCR for the diagnosis of Bovine Johne's disease (BJD) in lactating Indian dairy cattle," Research in Veterinary Science, vol. 84, no. 1, pp. 30-37, 2008.

[151] J. P. Bannantine, A. L. Paulson, O. Chacon et al., "Immunogenicity and reactivity of novel Mycobacterium avium subsp. paratuberculosis PPE MAP1152 and conserved MAP1156 proteins with sera from experimentally and naturally infected animals," Clinical and Vaccine Immunology, vol. 18, no. 1, pp. 105-112, 2011.

[152] R. E. Beam, K. D. Stottmeier, and G. P. Kubica, "Purified protoplasmic peptides of mycobacteria: isolation of speciesspecific peptides from protoplasm of mycobacteria," Journal of Bacteriology, vol. 100, no. 1, pp. 195-200, 1969.

[153] A. K. Mishra, N. N. Driessen, B. J. Appelmelk, and G. S. Besra, "Lipoarabinomannan and related glycoconjugates: structure, biogenesis and role in Mycobacterium tuberculosis physiology and host-pathogen interaction," FEMS Microbiology Reviews, vol. 35, no. 6, pp. 1126-1157, 2011.

[154] J. B. Osterstock, G. T. Fosgate, B. Norby, E. J. B. Manning, M. T. Collins, and A. J. Roussel, "Contribution of environmental mycobacteria to false-positive serum ELISA results for paratuberculosis," Journal of the American Veterinary Medical Association, vol. 230, no. 6, pp. 896-901, 2007.

[155] T. M. Eckstein, S. Chandrasekaran, S. Mahapatra et al., "A major cell wall lipopeptide of Mycobacterium avium subspecies paratuberculosis," Journal of Biological Chemistry, vol. 281, no. 8, pp. 5209-5215, 2006.

[156] G. M. Whitesides, "The origins and the future of microfluidics," Nature, vol. 442, no. 7101, pp. 368-373, 2006.

[157] X. Liu, K. Yang, A. Wadhwa, S. Eda, S. Li, and J. Wu, "Development of an AC electrokinetics-based immunoassay system for on-site serodiagnosis of infectious diseases," Sensors and Actuators A, vol. 171, no. 2, pp. 406-413, 2011.

[158] S. Neethirajan, I. Kobayashi, M. Nakajima, D. Wu, S. Nandagopal, and F. Lin, "Microfluidics for food, agriculture and biosystems industries," Lab on a Chip, vol. 11, no. 9, pp. 1574-1586, 2011.

[159] H. Jiang, X. Weng, and D. Li, "Microfluidic whole-blood immunoassays," Microfluidics and Nanofluidics, vol. 10, no. 5, pp. 941-964, 2011.

[160] A. H. C. Ng, U. Uddayasankar, and A. R. Wheeler, "Immunoassays in microfluidic systems," Analytical and Bioanalytical Chemistry, vol. 397, no. 3, pp. 991-1007, 2010.

[161] H. K. Hunt and A. M. Armani, "Label-free biological and chemical sensors," Nanoscale, vol. 2, no. 9, pp. 1544-1559, 2010.

[162] D. Qin, X. He, K. Wang, X. J. Zhao, W. Tan, and J. Chen, "Fluorescent nanoparticle-based indirect immunofluorescence microscopy for detection of Mycobacterium tuberculosis," Journal of Biomedicine and Biotechnology, vol. 2007, Article ID 89364, 9 pages, 2007. 

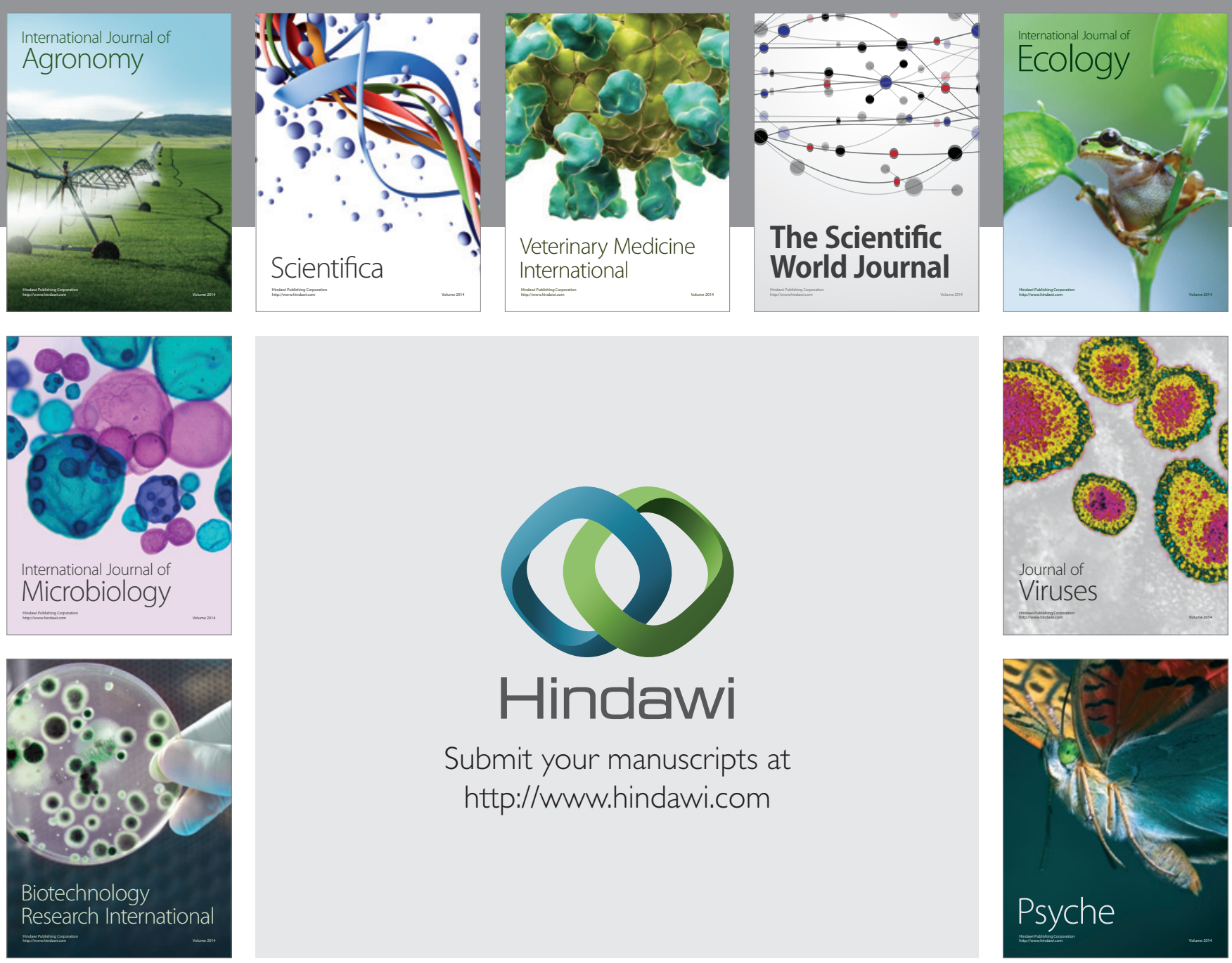

Submit your manuscripts at

http://www.hindawi.com
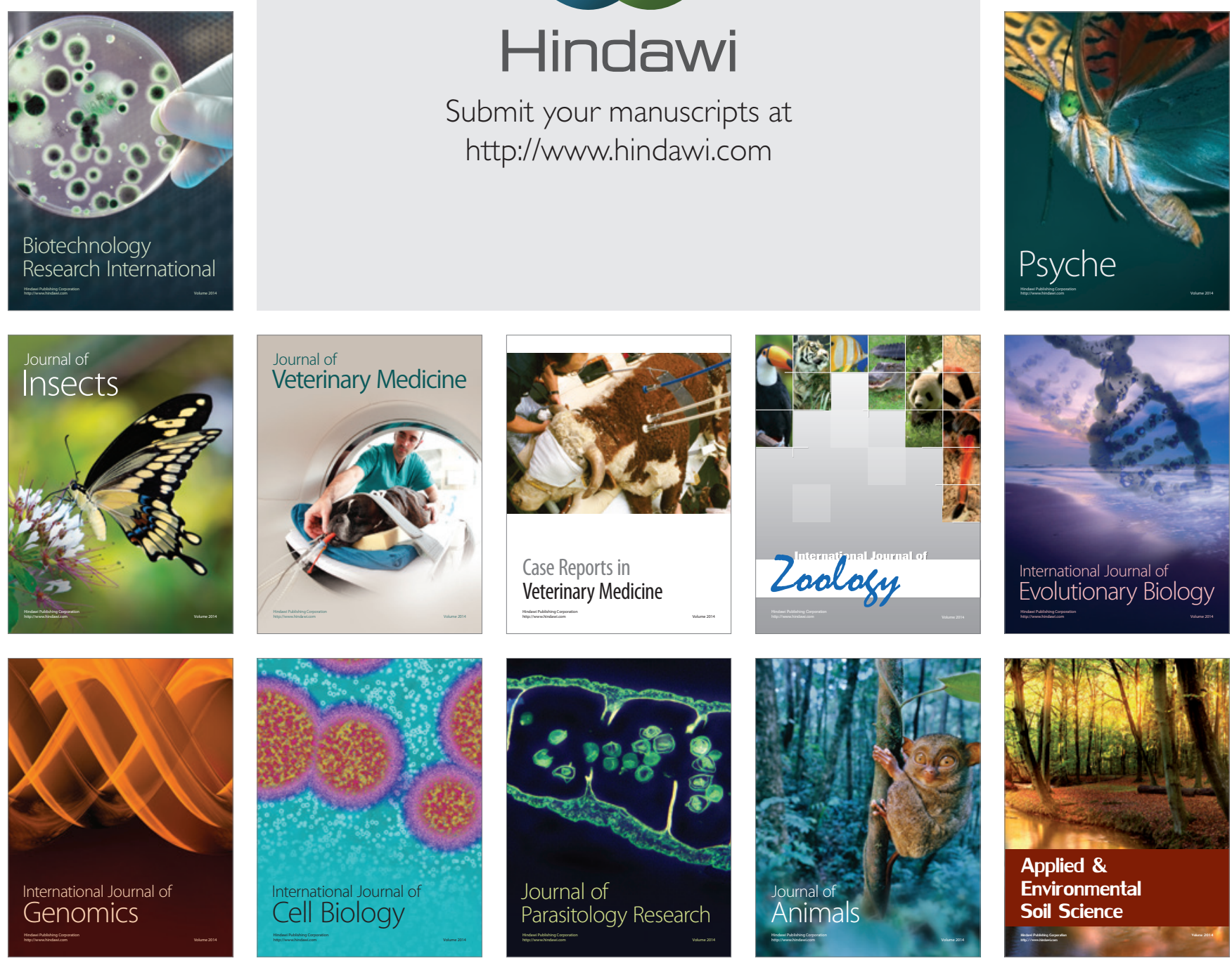